NASA

Technical

\section{Paper}

3182

February 1992

\title{
Eccentric and Concentric Muscle Performance \\ Following 7 Days of Simulated Weightlessness
}

Judith C. Hayes,

Mary L. Roper,

Augustus D. Mazzocca, John J. McBrine, Linda H. Barrows, Bernard A. Harris,

LAMGLEY RESEARCH CENTER
FP LIERARY MASA HALAPTON, VIRGGIIIA

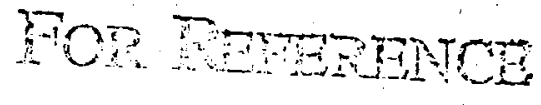

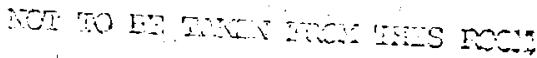



NASA

Technical

Paper

3182

1992

\section{Eccentric and Concentric Muscle Performance Following 7 Days of Simulated Weightlessness}

Judith C. Hayes,

Mary L. Roper, Augustus D. Mazzocca, John J. McBrine, and Linda $\mathrm{H}$. Barrows

KRUG Life Sciences

Houston, Texas

Bernard A. Harris and Steven F. Siconolfi

Lyndon B. Johnson Space Center Houston, Texas 



\section{CONTENTS}

\section{Page}

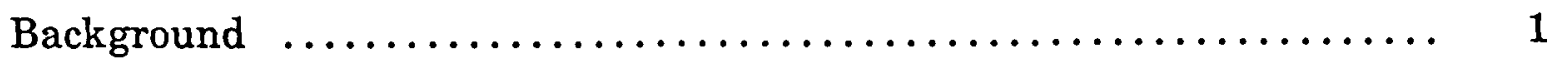

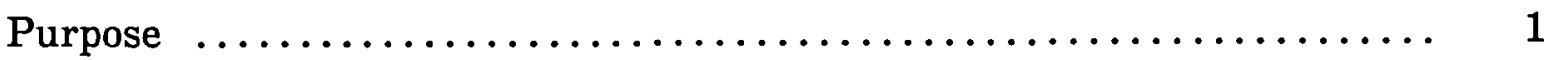

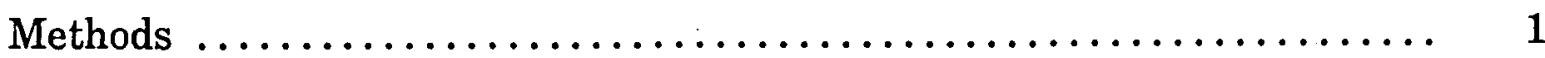

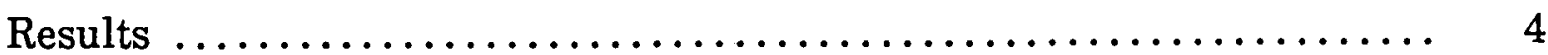

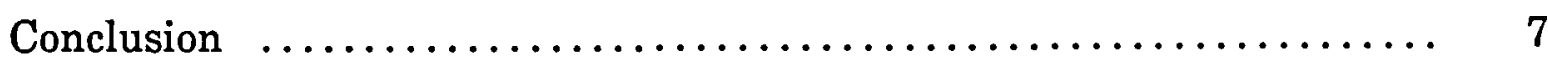

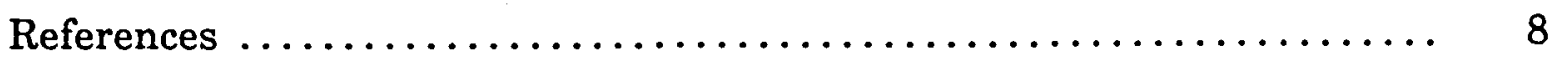




\section{FIGURES}

Page

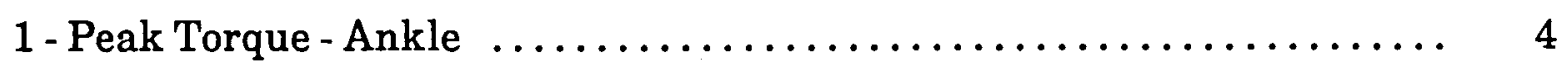

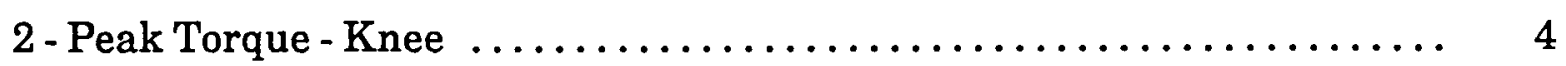

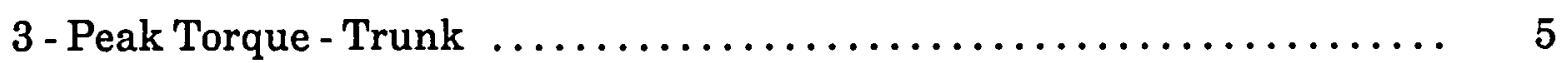

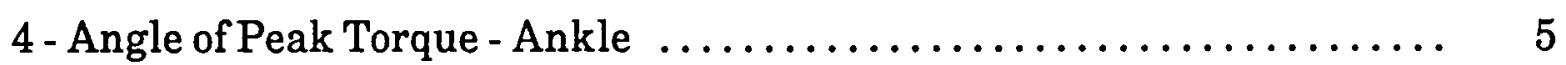

5 - Angle of Peak Torque - Knee $\ldots \ldots \ldots \ldots \ldots \ldots \ldots \ldots \ldots \ldots \ldots \ldots \ldots \ldots \ldots \ldots \ldots$

6 - Angle of Peak Torque - Trunk ....................... 6 


\section{BACKGROUND}

The microgravity induced alterations in skeletal muscle performance have yet to be clearly understood. However, the operational significance of these alterations has intensified due to planned extension of space mission duration [8]. Biomedical research has indicated that space flight and bed rest have shown analogous changes in muscle function $[1,2,3,6,9]$. Thus, bed rest often is utilized as a predictive prototypical scenario to simulate the physiological adaptations that occur as a result of extended duration exposure to a microgravity environment $[2,3,4,5]$.

Ordinary activities of daily living on the Earth generate both concentric and eccentric muscle contractions. Generally, concentric contractions are performed against gravity, while eccentric contractions are completed with gravity. Therefore, reducing the effects of gravity, as in space flight or bed rest, may result in an imbalance between concentric and eccentric contractions that may contribute to skeletal muscle atrophy and/or dysfunction [2].

Skeletal muscle performance tests utilizing isokinetic dynamometers offer the capability for standardized measurements of dynamic concentric and eccentric actions of a variety of muscle groups. Such devices provide sophisticated systems for the documentation and analysis of isokinetic muscle performance data throughout the arc of motion of the particular joint while maintaining a preset constant angular velocity. The utilization of recent software and hardware technological advances yields an increased capability to characterize the force-velocity relationships of specific dynamic skeletal muscle actions.

\section{PURPOSE}

The purpose of this study was to determine changes in skeletal muscle performance of the lower extremity and torso prior to and immediately after seven days of simulated (horizontal bed rest) weightlessness.

\section{METHODS}

Subjects. Eleven male test subjects participated in skeletal muscle performance tests prior to and following seven days of complete, horizontal bed rest. Each subject had a screening examination similar to an Air Force Class III physical examination and signed the NASA Human Research Consent Form. None of the subjects had a history of 
musculoskeletal dysfunction in any of the measured joints. The test subject characteristics are described in the table below.

\section{Test Subject Characteristics}

$\begin{array}{lrr} & \frac{\text { Mean }}{\text { SD }} \\ \text { Age (yr) } & 33.8 & \pm 4.9 \\ \text { Height }(\mathrm{cm}) & 177.2 & \pm 7.4 \\ \text { Weight }(\mathrm{kg}) & 81.4 & \pm 12.1 \\ \text { Fat }(\%) & 16.1 & \pm 7.4 \\ \mathrm{VO}_{2 \mathrm{max}}(\mathrm{mL} / \mathrm{kg} / \mathrm{min}) & 43.6 & \pm 6.2\end{array}$

Procedures. The BIODEX Multi-joint Isokinetic Dynamometer was utilized to measure maximum voluntary concentric and eccentric contractions for flexion and extension of the trunk, knee, and ankle. The trunk and dominant knee and ankle were tested [7]. Each joint test was preceded by standardized stretching and warm-up for the involved muscle groups. Post-bed rest tests were administered at the same time of day as pre-bed rest tests and occurred within three hours of reambulation.

Trunk. The test subjects were seated and securely restrained in the BIODEX Back System. The fixed axis of the powerhead of the dynamometer was aligned with the anterior superior iliac spine of each subject. The subjects were firmly restrained at the chest, hips, and thighs with the knees flexed and feet dangling. Trunk flexion and extension were tested in the sagittal plane, isolating all other movement. A reference angle of $90^{\circ}$ was set at $90^{\circ}$ flexion for the trunk. A 2-3 repetition warm-up was required prior to each test. The isokinetic concentric test included three maximal voluntary contractions at the angular velocity of $75 \% \mathrm{sec}$ to evaluate back and abdomen strength. The isokinetic eccentric test included three maximal voluntary contractions at the angular velocity of $75 \%$ sec with a two-second pause between directions, allowing a maximal isometric contraction to precede the onset of each eccentric action. Adequate rest (at least one minute) was provided between concentric and eccentric tests.

Knee. The test subjects were seated and securely restrained with thigh and hip stabilization straps. A shin pad fastened the lower leg to the knee attachment. The fixed axis of the powerhead of 
the dynamometer was aligned transversely at the femoral condyle of each subject, halfway between the patella and the posterior of the knee. The shin pad was placed immediately superior to the medial malleolus. A reference angle of $0^{\circ}$ was set at full extension for the knee. Knee flexion and extension were tested in the sagittal plane. A 2-3 repetition warm-up was required prior to each test. The isokinetic concentric test included three maximal voluntary contractions at the angular velocity of $30 \% \mathrm{sec}$ to evaluate quadriceps and hamstring strength. The isokinetic eccentric test included three maximal voluntary contractions at the angular velocity of $30 \% \mathrm{sec}$ with a two-second pause between directions, allowing a maximal isometric contraction to precede the onset of each eccentric action. Adequate rest (at least one minute) was provided between concentric and eccentric tests.

Ankle. The test subjects were kneeling and securely restrained with the knee flexed at $90^{\circ}$ and held in place with the thigh strap. The foot/ankle straps stabilized the joint throughout the entire range of motion of plantar and dorsiflexion. The fixed axis of the powerhead of the dynamometer was aligned at the axis of rotation of the ankle of each subject, passing obliquely through the tip of the lateral and medial malleoli. Ankle plantar and dorsiflexion were tested in stocking feet with the foot positioned flat on the footplate attachment. A reference angle of $90^{\circ}$ was set at $90^{\circ}$ flexion for the ankle. A 2-3 repetition warm-up was required prior to each test. The isokinetic concentric test included three maximal voluntary contractions at the angular velocity of $30^{\circ} / \mathrm{sec}$ to evaluate gastrocnemius/soleus and tibialis anterior strength. The isokinetic eccentric test included three maximal voluntary contractions at the angular velocity of $30 \% \mathrm{sec}$ with a two-second pause between directions, allowing a maximal isometric contraction to precede the onset of each eccentric action. Adequate rest (at least one minute) was provided between concentric and eccentric tests.

The highest concentric and eccentric peak torques and their corresponding angles of peak torque were measured and recorded at the trunk, knee, and ankle for flexion and extension. Data were evaluated by univariate ANOVA. Post hoc analyses compared contraction type (concentric and eccentric) and time (pre- and post-test). 


\section{RESULTS}

Eccentric peak torque was significantly $(p<0.05)$ greater than concentric peak torque for the ankle (Figure 1) and knee (Figure 2). Eccentric peak torque was significantly $(\mathrm{p}<0.05)$ greater than concentric peak torque in the abdomen pre- and post-bed rest. Eccentric back peak torque was significantly $(\mathrm{p}<0.05)$ larger than concentric back peak torque post-bed rest; however, although pre-bed rest back peak torque was observed to be greater eccentrically than concentrically, the difference was not statistically significant (Figure 3).

Tibialis Anterior

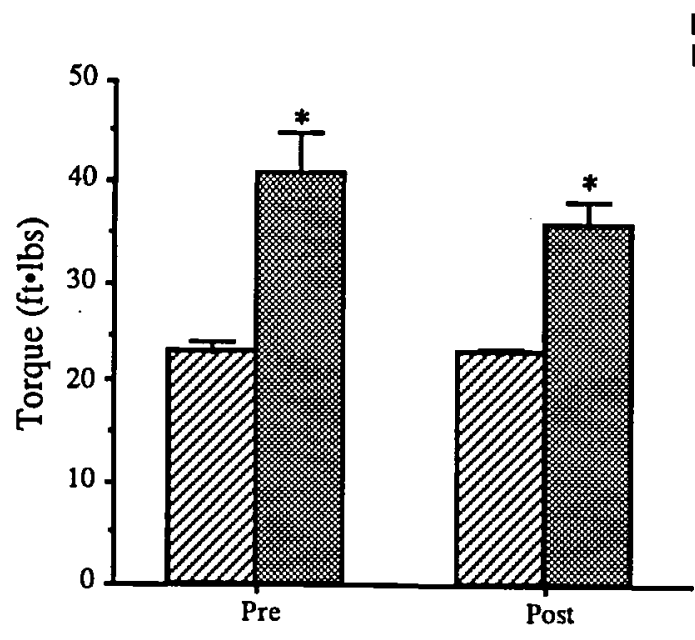

\section{Gastrocnemius/Soleus}

Concentric

Eccentric

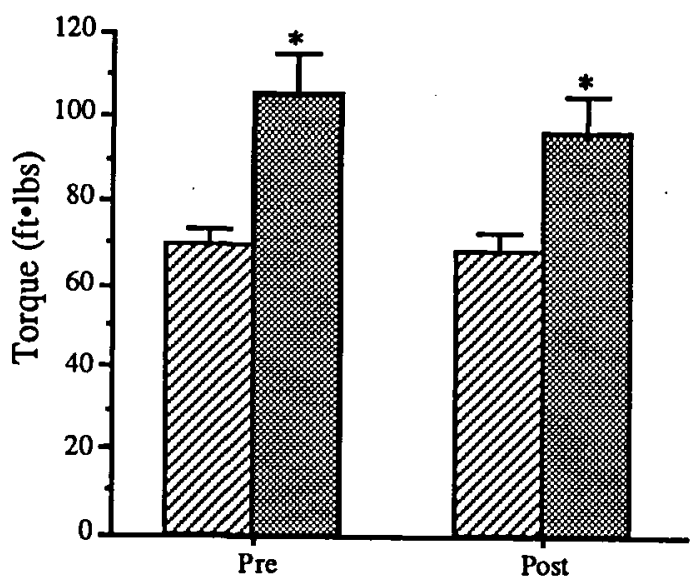

*Eccentric $>$ Concentric $(p<0.05)$

Figure 1 - Peak Torque - Ankle Quadriceps

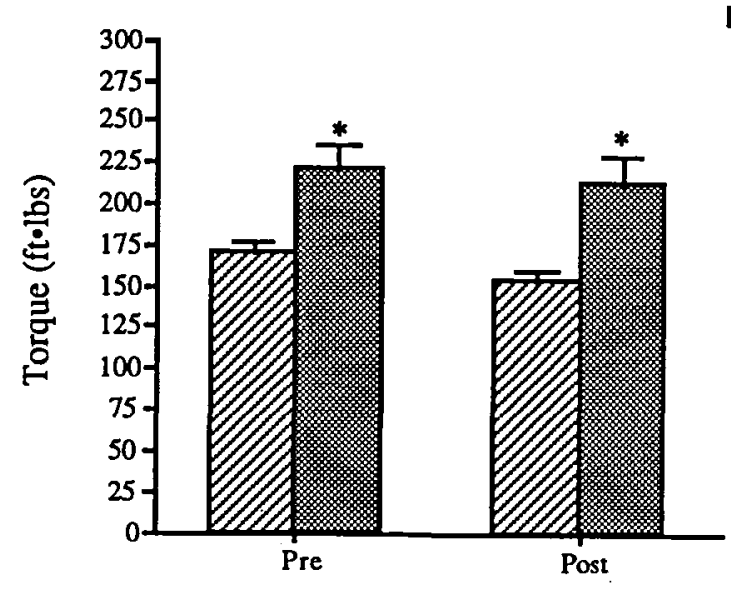

Q Concentric

Hamstrings Eccentric

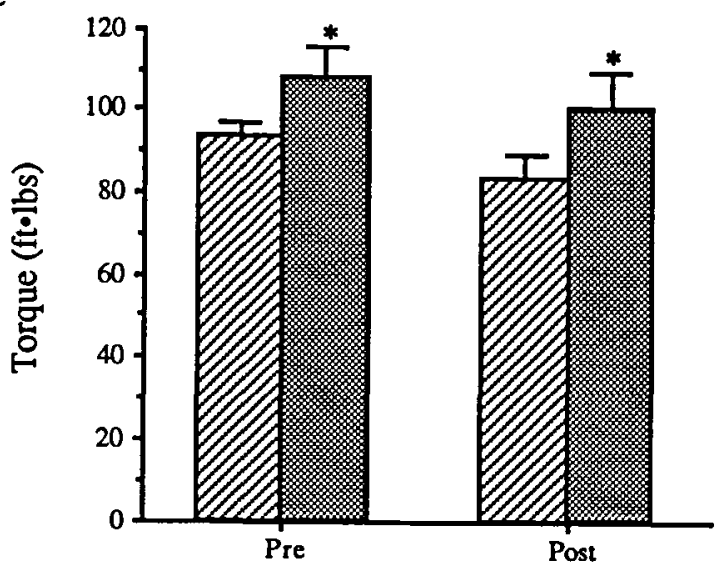

*Eccentric $>$ Concentric $(\mathrm{p}<0.05)$

Figure 2 - Peak Torque - Knee 


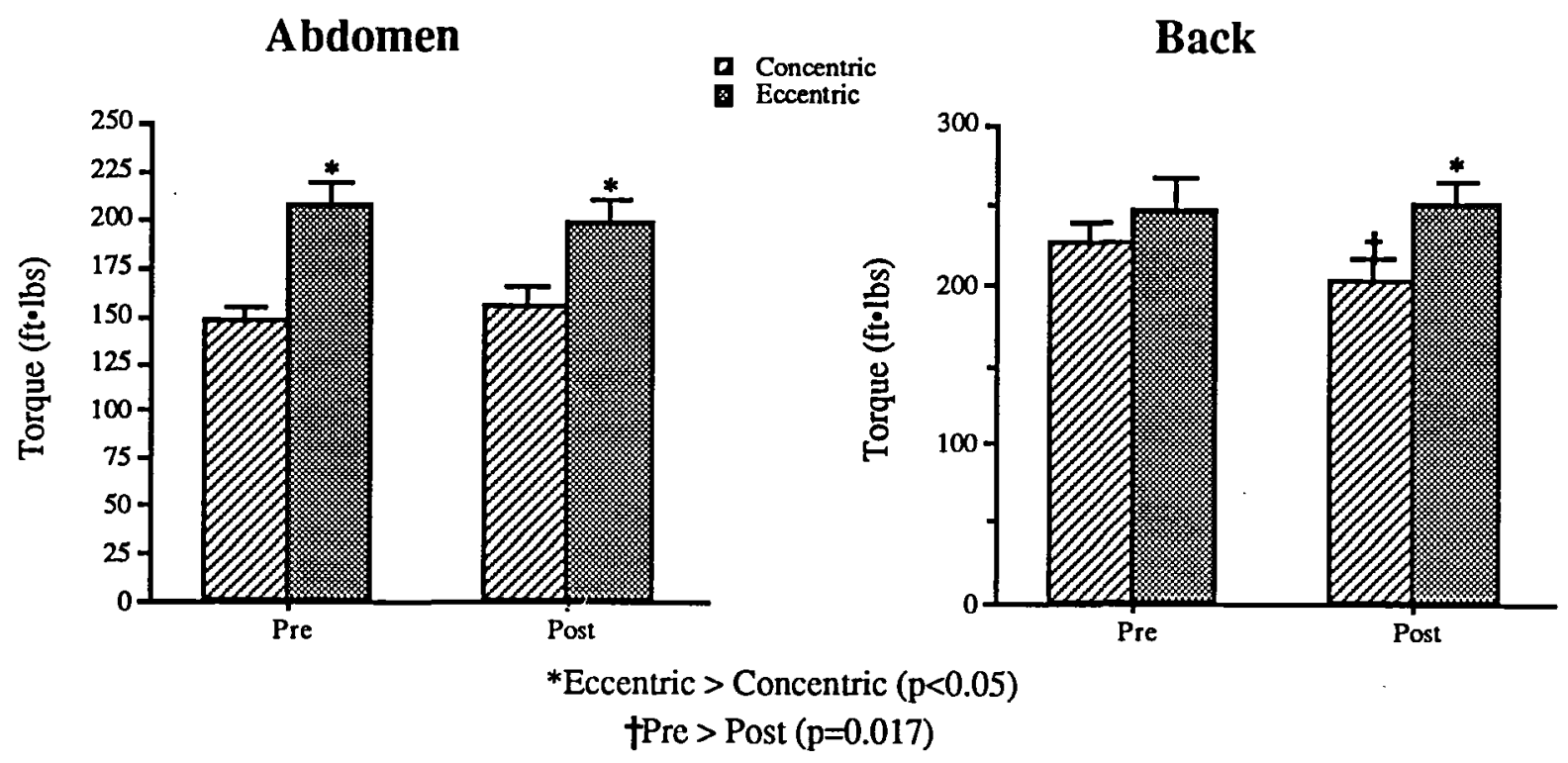

Figure 3 - Peak Torque - Trunk

A bed rest induced decrease in peak torque was significant $(p=0.017)$ only in the concentric back strength (Figure 3). All of the anterior muscle groups had angles of peak torque of approximately $60^{\circ}$ (Figures $4,5,6)$, while the angle of peak torque for the posterior muscles varied from $24-97^{\circ}$.

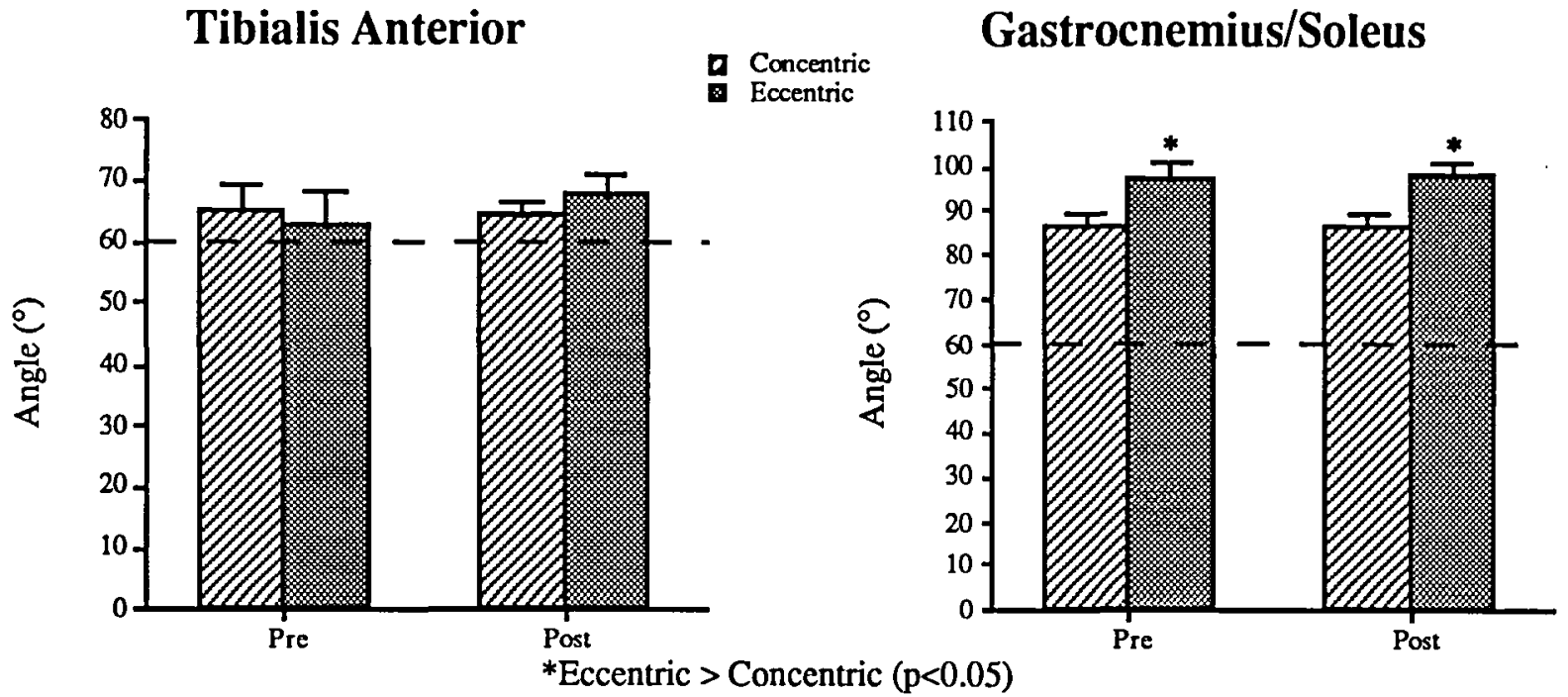

Figure 4 - Angle of Peak Torque - Ankle 


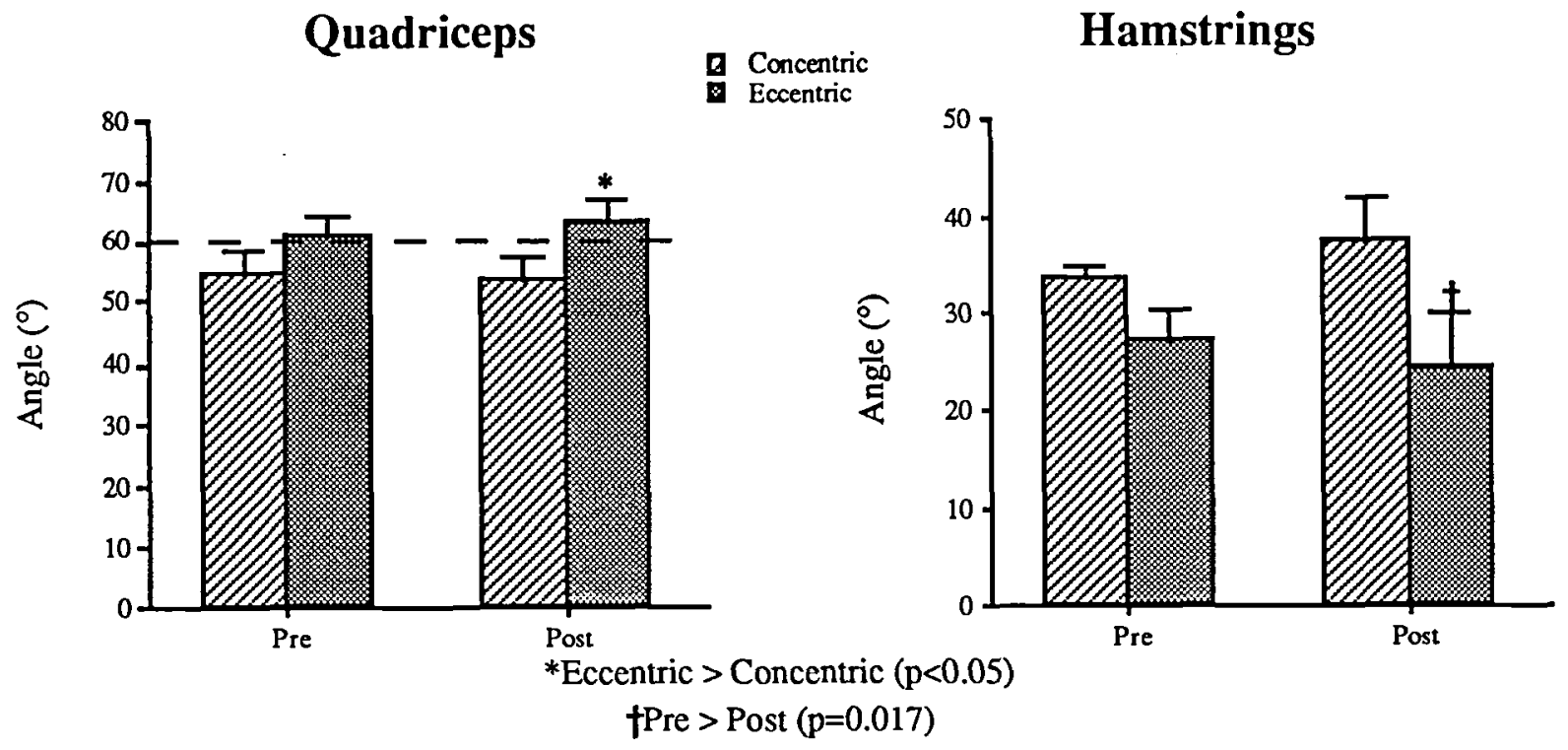

Figure 5 - Angle of Peak Torque - Knee
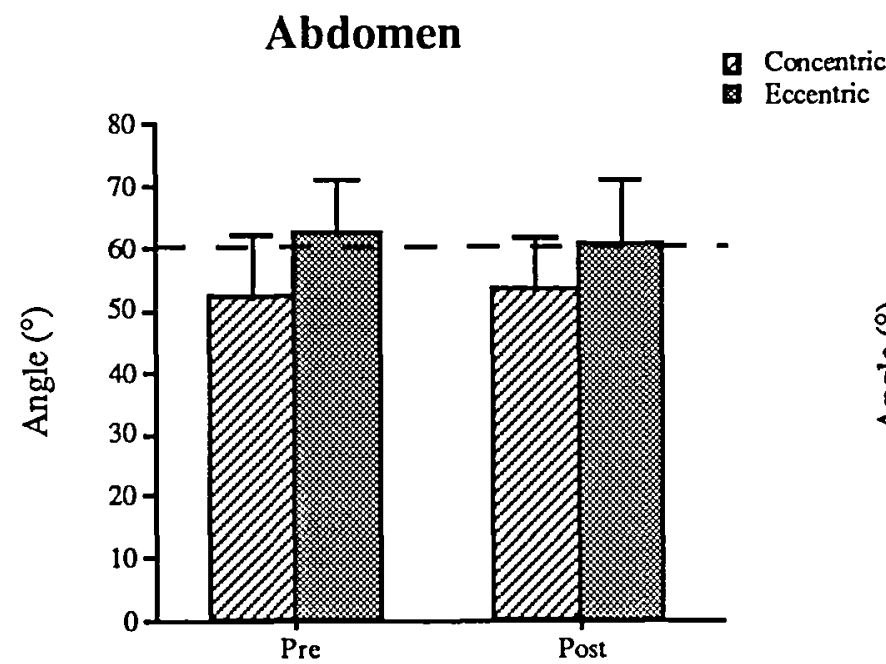

Back

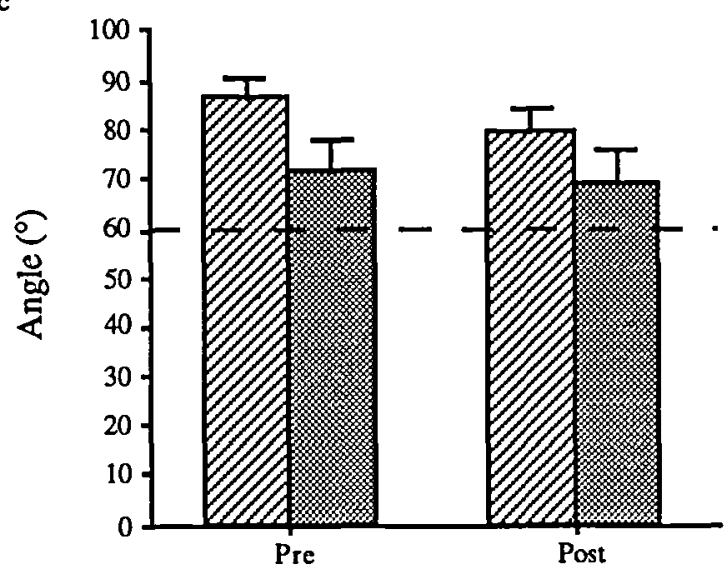

Figure 6. Angle of Peak Torque - Trunk

Following bed rest, the quadriceps muscle group showed that the eccentric angle of peak torque was significantly different $(p<0.05)$ from the concentric angle of peak torque. The eccentric angle of peak torque changed $(p=0.017)$ when comparing pre- to post-bed rest. The gastrocnemius/soleus maintained its pre-bed rest differences in angle of peak torque. The back, abdomen, and tibialis anterior showed no significant deviations pre- or post-bed rest. (Figures $4,5,6$ ) 


\section{CONCLUSION}

This study suggests that changes in angle of peak torque following bed rest may biomechanically effect the functional performance in the lower extremities, while decreases in concentric back strength may affect postural stability. Should analogous changes occur following space flight, operational effectiveness may be altered, thereby jeopardizing crew health and safety. 


\section{REFERENCES}

1. Booth, F. W. and Gollnick, P. D. Effects of disuse on the structure and function of skeletal muscle. Med. Sci. Sports Med. 15:415-420, 1983.

2. Convertino, V. A. Physiological adaptations to weightlessness: Effects on exercise and work performance. Exer. Sport Sci. Review Vol. 18, 1990.

3. Dudley, G. A., Gollnick, P. D., Convertino, V. A., and Buchanan, P. Changes of muscle function and size with bed rest. The Physiologist 32(1):565-566, 1989.

4. Greenleaf, J. E., Van Beaumont, W., Convertino, V. A., and Starr, J. C. Handgrip and general muscular strength and endurance during prolonged bed rest with isometric and isotonic leg exercise training. Aviat. Space Environ. Med. 54(8):696-700, 1983.

5. LeBlanc, A., Gogia, P., Schneider, V., Krebs, J., Schonfeld, E., and Evans, H. Calf muscle area and strength changes after five weeks of horizontal bed rest. Am. J. Sports Med. 16(6):624-629, 1988.

6. Leonard, J. I., Leach, C. S., and Rambaut, P. C. Quantitation of tissue loss during prolonged space flight. Am. J. Clin. Nutr. 38:667-679, 1983.

7. Roper, M. L., Hayes, J. C., Mazzocca, A. D., Barrows, L. H., Harris, B. A., and Siconolfi, S, F. Optimal angular velocities for concentric and eccentric contractions (Abstract). Proceedings of the 61st Annual Meeting of the Aerospace Medical Association, New Orleans, 1990.

8. National Research Council. A Strategy for Biology and Medical Sciences for the 1980s and 1990s. Washington: National Academy Press, 1987.

9. Thornton, W. E. and Rummel, J. A. Muscular deconditioning and its prevention in space flight. In: Johnston, R. S. and Dietlein, L. F. (eds.) Biomedical Results from Skylab (NASA SP-377). Washington: U.S. Government Printing Office, 1977. 





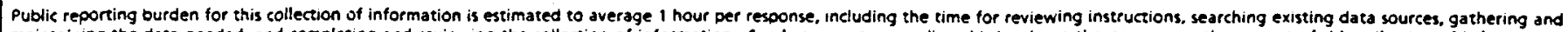

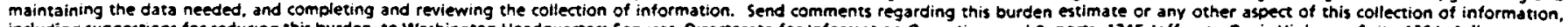

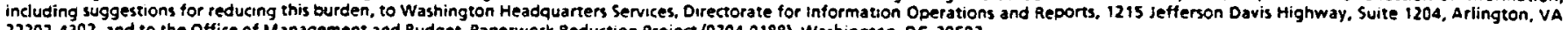
22202-4302, and to the Office of Management and Budget, Paderwork Reduction Project (0704-0188), Washingron, OC 20503.

\begin{tabular}{|l|l|l|l|}
\hline 1. AGENCY USE ONLY (Leave blank) & $\begin{array}{l}\text { 2. REPORT DATE } \\
\text { February } 1992\end{array}$ & $\begin{array}{l}\text { 3. REPORT TYPEAND DATES COVERED } \\
\text { TeChnical Paper }\end{array}$ \\
\hline
\end{tabular}

4. TITLEANO SUBTITLE Concentric Muscle Performance Following 7 Days of Simulated Weightlessness

5. FUNDING NUMBERS

6. AUTHOR(S)

Judith C. Hayes, Mary L. Roper, Augustus D. Mazzocca, John J. McBrine, Linda H. Barrows, Bernard A. Harris, and Steven F. Siconolfi

7. PERFORMING ORGANIZATION NAME(S) AND ADDRESS(ES)

Medical Sciences Division

Space Biomedical Research Institute

National Aeronautics and Space Administration

Johnson Space Center

Houston, Texas 77058

9. SPONSORING /MONITORING AGENCY NAME(S) AND ADDRESS(ES)

National Aeronautics and Space Administration

Washington, D. C. 20546-001

8. PERFORMING ORGANIZATION S-665

11. SUPPLEMENTARY NOTES

KRUG Life Sciences: J.C.Hayes, M.L.Roper, A.D.Mazzocca, J.J.McBrine, and L.H.Barrows Johnson Space Center: B.A.Harris and S.F.Siconolfi

12a. DISTRIBUTIONIAVAILABILITY STATEMENT

Unclass if ied/Unlimited

Subject Category 52

13. ABSTRACT (Maximum 200 words)

Changes in skeletal muscle strength occur in response to chronic disuse or insufficient functional loading. The purpose of this study was to examine changes in muscle performance of the lower extremity and torso prior to (PRE) and immediately after (POST) 7 days of simulated weightlessness (horizontal bed rest). A Biodex was used to determine concentric (CON) and eccentric (ECC) peak torque (PT) and angle at peak torque (APT) for the back (BK), abdomen (AB), quadriceps (Q), hamstring (H), soleus (S), and tibialis anterior (TA). A reference angle of 0 degrees was set at full extension. Data were analyzed by ANOVA.

\begin{tabular}{|c|c|c|c|}
\hline $\begin{array}{l}\text { 14. SUBJECT TERMS } \\
\text { mUSCle performanc }\end{array}$ & imulated weightles & horizontal bed rest, & $\begin{array}{l}\text { 15. NUMBER OF PAGES } \\
12\end{array}$ \\
\hline concentric at & - que & + & $\begin{array}{l}\text { 16. PRICE COOE } \\
\mathrm{AO} 3\end{array}$ \\
\hline $\begin{array}{l}\text { 17. SECURITY CLASSIFICATION } \\
\text { OFREPORT } \\
\text { UnClaSs if ied }\end{array}$ & $\begin{array}{l}\text { 18. SECURITY CLASSIFICATION } \\
\text { OF THIS PAGE } \\
\text { UnClaSS if ied }\end{array}$ & $\begin{array}{l}\text { 19. SECURITY CLASSIFICATION } \\
\text { OFABSTRACT } \\
\text { UnClaSS if ied }\end{array}$ & $\begin{array}{l}\text { 20. LIMITATION OFABSTRACT } \\
\text { UL }\end{array}$ \\
\hline
\end{tabular}



